\title{
The Evaluation And Analysis For Performance Of Agricultural Listed Companies
}

\author{
Yan-li Shen \\ School of Economics and Managemen,Shenyang Agricultural University, Liaoning Province, China \\ School of Managemen,Shenyang Institute of Engineering, Liaoning Province, China (Email:syhard@163.com)
}

\begin{abstract}
By the end of 2012, There are 49 Agricultural Ashare listed companies in Shanghai and Shenzhen Stock Exchange. In this paper, From a listed company's profitability, solvency, development capacity and operational abilities, select the affected performance indicators of listed companies, in order to build performance evaluation system, using factor analysis of the performance analysis on agricultural companies. To operate the results of listed companies on the agricultural comprehensive evaluation and to sort the agricultural listed companies, finding the causes of poor operating performance, and try to improve the operating performance of agriculture listed companies.
\end{abstract}

Index Terms - Agriculture companies; financial performance; factor analysis; performance Evaluation.

\section{Introduction}

According to the classification of listed companies in China Securities Regulatory, Agriculture listed company is the industry guidelines of the agriculture, as defined in the agriculture, forestry, animal husbandry and services,excluding the food industry and beverage industry. In this paper, the agricultural A-share listed companies excluds ST listed companies and companies with incomplete data. Selecting 30 in 2012 as the analysis of samples of agricultural listed companies.The main financial indicators and data from Wind Information, Advisory Network of China's listed companies, Sina Finance, NetEase and other sites.

In this paper, using multivariate statistics, factor analysis to analyse agricultural listed company performance on empirical method. By extracting the common factor, to evaluate listed company performance, according to the listed companies in each factor score and the corresponding weight, calculate its consolidated performance score, and to operate performance of listed companies of agriculture.

\section{The Empirical Analysis}

By SPSS statistical software for data processing, to select eigenvalue> 1 common factors, automatically generate a public factor's scores,namely F1, F2, Fi, as formula: composite score $=(\mathrm{a} 1 \times \mathrm{F} 1 \mathrm{a} 2 \times \mathrm{F} 2 \mathrm{a} 3 \times \mathrm{F} 3 \ldots$ ai $\times \mathrm{Fi}) /(\mathrm{a} 1 \mathrm{a} 2$ a3 ... ai), (where ai is the $i$-th eigenvalue of the public contribution factor), finally to find the listing of the company's operating performance score.

This will be 12 indicators of performance ,clouding the main profit margins, return on assets, return on equity, current ratio, quick ratio, asset liability ratio, accounts receivable turnover, inventory turnover, total asset turnover, the main revenue growth rate, net profit growth, total assets growth rate, thoes indicators reflects the performance of listed companies .finally to calculate the total performance score and specific analyse based on this sample of 30 agricultural performance.

\section{A. Factor Analysis}

\section{1) Test the applicability}

In this paper, Bartlett sphericity test and KMO test about factor analysis is tested feasibility, the test results in Table 1.

Table I KMO and Bartlett's Test

\begin{tabular}{|c|c|c|}
\hline KMO statistic & Bartlett sphericity test & .508 \\
\hline & approximate chi-square value(Approx. Chi-Square) & 196.4 \\
\hline & Degrees of freedom (df) & 66 \\
\hline & Significance level (Sig.) & .000 \\
\hline
\end{tabular}

Test results shows that measure is 0.508 ton the original variables in the KMO, than 0.5; In addition, Bartlett test of sphericity approximate chi-square is 196.407 , degrees of freedom is 66 , significance level is 0.000 , less than $1 \%$, The correlation matrix shows variable correlation of the selected sample data ,It may be analysed for factor model.

\section{2) To determine the number of common factors}

Common factor is extracted among the indicators of the original information, reflecting the target public information with a clear explanation. The original index can be expressed as a common factor loading (ie, common factor coefficient) multiplied by common factors and common factors and the special role and form factor. Contribution of common factors in the model is the common factor in the square and all the load, the common factor contribution rate equal to the corresponding eigenvalue of the factor accounting for the proportion of eigenvalues, that is the factor accounting for the original information reflected in the proportion of all the original information.

In this study, using principal component analysis to solve the initial common factor eigenvalues, variance contribution rate and the cumulative variance contribution rate about 2012 financial data (Table 2) 
Table 2 Total Variance Explained

\begin{tabular}{|c|c|c|c|c|c|}
\hline & Total & Variance \% & Cumulative \% & Cumulative \% & Cumulative \% \\
\hline 1 & 3.446 & 28.72 & 28.721 & 28.721 & 22.973 \\
\hline 2 & 2.660 & 22.16 & 50.885 & 50.885 & 44.876 \\
\hline 3 & 1.597 & 13.31 & 64.191 & 64.191 & 62.417 \\
\hline 4 & 1.165 & 9.710 & 73.901 & 73.901 & 73.901 \\
\hline 5 & .922 & 7.685 & 81.586 & & \\
\hline 6 & .697 & 5.812 & 87.398 & & \\
\hline 7 & .640 & 5.336 & 92.733 & & \\
\hline 8 & .357 & 2.974 & 95.707 & & \\
\hline 9 & .231 & 1.926 & 97.633 & & \\
\hline 10 & .170 & 1.415 & 99.049 & & \\
\hline 11 & .073 & .609 & 99.658 & & \\
\hline 12 & .041 & .342 & 100.000 & & \\
\hline
\end{tabular}

Extraction Method: Principal Component Analysis.

According to a common factor eigenvalues is greater than 1 , using principal component analysis to extract the main factors, the results shown in Figure 1

Performance characteristics of each component before rotation value of gravel map

Scree Plot

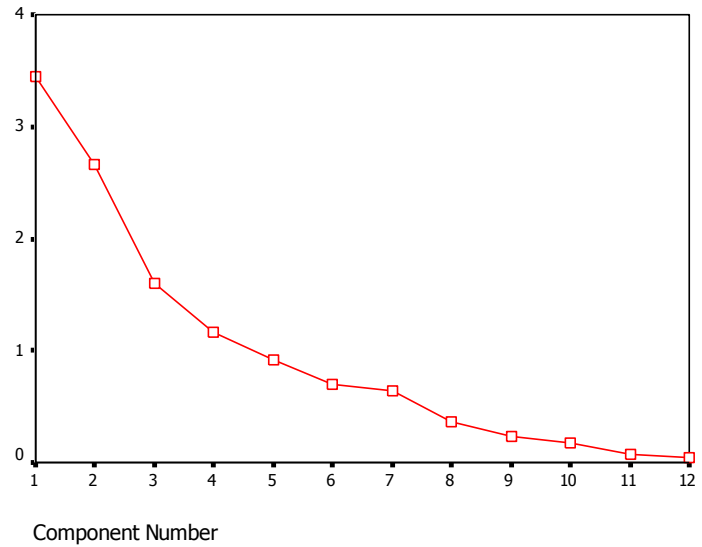

Figure 1 characteristic values of each component before rotation

In the figure, the characteristic curves in the fourth factor has shown a significant "turning point", the first four factors were eigenvalues greater than 1 , and from the first five factors began, eight factors are the eigenvalues, the gap is less than 1 ,therefore, we selected the first four factors to represent the original variables.

Eigenvalues of the correlation coefficient matrix and the contribution rate haen been Calculated by SPSS softwe. As can be seen from Table 3, in the selected 12 indicators, the first four common factors may reflect $66.3 \%$ of the information they explained the agricultural companies of the consolidated financial indicators score $66.3 \%$.
Table 3 Communalities

\begin{tabular}{|l|l|c|}
\hline & Initial & Extraction \\
\hline $\mathrm{X} 1$ & 1.000 & .836 \\
\hline $\mathrm{X} 2$ & 1.000 & .669 \\
\hline $\mathrm{X} 3$ & 1.000 & .852 \\
\hline $\mathrm{X} 4$ & 1.000 & .663 \\
\hline $\mathrm{X} 5$ & 1.000 & .861 \\
\hline $\mathrm{X} 6$ & 1.000 & .850 \\
\hline $\mathrm{X} 7$ & 1.000 & .907 \\
\hline $\mathrm{X} 8$ & 1.000 & .610 \\
\hline $\mathrm{X} 9$ & 1.000 & .867 \\
\hline $\mathrm{X} 10$ & 1.000 & .672 \\
\hline $\mathrm{X} 11$ & 1.000 & .673 \\
\hline $\mathrm{X} 12$ & 1.000 & .607 \\
\hline
\end{tabular}

As can be seen from Table 3 the common degree of the original variables is between $61 \%-90.2 \%$, indicating that the variance in the original variables can be explained four public factors on large part of the proportion of the original variables, it can be extracted four common factors .Have determined the coefficient of the extracted common factors, and then extracte the four main factors F1, F2, F3, F4, then establish factor loading matrix.

Table 4 Rotated factor loading matrix

\begin{tabular}{|l|l|l|l|l|}
\hline \multirow{2}{*}{ Evaluation indicator } & \multicolumn{4}{l}{ Factor loading } \\
\cline { 2 - 5 } & $\mathrm{F} 1$ & $\mathrm{~F} 2$ & $\mathrm{~F} 3$ & $\mathrm{~F} 4$ \\
\hline Earnings per share & .807 & .423 & .076 & .013 \\
\hline ROE & .438 & .632 & -.273 & .058 \\
\hline Return on total assets & .849 & .175 & .282 & .146 \\
\hline Asset-liability ratio & .161 & -.630 & .108 & .478 \\
\hline Current ratio & .110 & .891 & -.164 & .171 \\
\hline Quick Ratio & .137 & .883 & .154 & .163 \\
\hline Inventory turnover rate & .008 & -.029 & .952 & .009 \\
\hline Accounts receivable turnover & .053 & .082 & .696 & .542 \\
\hline The total asset turnover & .326 & -.162 & .856 & .032 \\
\hline Earnings per share growth & .753 & -.110 & .306 & .011 \\
\hline Main business revenue growth & .167 & .040 & .175 & .803 \\
\hline Operating profit growth & .658 & -.034 & -.178 & .205 \\
\hline
\end{tabular}

3) The establishment of factor loading matrix and the rotation

Factor loading indicates the closeness between Financial variables and between the common factor. From the factor loading matrix to identify each common factor that represents the original indicators, we can give a reasonable economic interpretation of these factors.

However, if the amount of factor loading is more evenly, it is difficult to determine which indicators are more closely 
linked with the factor, in order to, clearly explain the common factor, the factor usually be rotated, the rotated factor loading matrix of the target in only one common factor have a greater load, while the remaining common factor load is smaller, By the maximum variance orthogonal rotation method, rotated factor loading matrix as shown in Table 4. From the factor analysis principle, Wo extracted four common factors (F1, F2, F3, F4) between unrelated, between each common factor and the various indicators that factors representing is highly relevant.

\section{4) Explaining Factors}

As can be seen from Table 5, the first common factor F1 in earnings per share $\mathrm{X} 1$, return on assets $\mathrm{X} 3$, earnings per share growth rate $\mathrm{X} 10, \mathrm{X} 12$ on operating profitgrowth with a large load, the load values is above 0.6 , these two indicators multi-angle reflect the performance of agricultural listed company on earnings and profitability, it can be called the profit factor.

The second common factor $\mathrm{F} 2$ in the asset-liability ratio $\mathrm{X} 4$, current ratio $\mathrm{X} 5, \mathrm{X} 6$ quick ratio indicators with a high load, the load values is above 0.6 , these three indicators reflect the company's solvency, including the company's short-term solvency and long-term solvency, it can be called the debt factor.

The third common factor F3 in the inventory turnover rate of $X 7, X 9$ has a high total asset turnover load, the load is greater than 0.8 , to reflect the company's operating efficiency, can be called operational factors.

The fourth common factor F4 in the main business revenue growth with a high load on the X11 target, the load values is above 0.8 , it is mainly to reflect the operating performance of listed companies in agriculture, the main business of the level of increased earnings, can be called for the main business income of the development factor.

\section{B. Factor Score}

Thus, the naming of performance on Agriculture listed companies and explaining on economic factors have been completed, the name of the main factors and variables included are in Table 5

Table 5 Component Score Coefficient Matrix

\begin{tabular}{|c|c|c|c|c|}
\hline & \multicolumn{4}{|c|}{ Component } \\
\cline { 2 - 5 } & 1 & 2 & 3 & 4 \\
\hline Earnings per share & .275 & .088 & -.021 & .027 \\
\hline Return on net assets & .135 & .198 & -.131 & .079 \\
\hline Return on total assets & .304 & -.021 & .046 & -.109 \\
\hline Asset-liability ratio & -.018 & -.194 & .037 & .305 \\
\hline Current ratio & -.044 & .343 & -.014 & -.046 \\
\hline Quick Ratio & -.204 & .444 & .206 & .233 \\
\hline Inventory turnover rate & -.127 & .091 & .502 & .044 \\
\hline Accounts receivable turnover & -.002 & -.008 & .323 & -.261 \\
\hline The total asset turnover & .046 & -.026 & .390 & -.007 \\
\hline Earnings per share growth & .293 & -.118 & .048 & -.033 \\
\hline Main business revenue growth & .010 & .099 & .119 & .598 \\
\hline Operating profit growth & .299 & -.101 & -.175 & .114 \\
\hline
\end{tabular}

Extraction Method: Principal Component Analysis.

By the factor score coefficient matrix, wo obtained factor score function:

$\mathrm{F} 1=0.275 \mathrm{X} 1+0.135 \mathrm{X} 2+0.304 \mathrm{X} 3-0.018 \mathrm{X} 4-0.044 \mathrm{X} 5-$ $0.204 X 6-0.127 \times 7-0.002 \times 8+0.046 \times 9+0.293 \times 10+0.01 \times 11$ $+0.299 \mathrm{X} 12$

$\mathrm{F} 2=0.088 \mathrm{X} 1+0.198 \times 2-0.021 \times 3-0.194 \times 4+0.343 \times 5+$ $0.444 \times 6+0.091 \times 7-0.008 \times 8-0.026 \times 9-0.118 \times 10+0.099 \times 11-$ $0.101 \times 12$

$\mathrm{F} 3=-0.021 \times 1-0.131 \mathrm{X} 2+0.046 \times 3+0.037 \mathrm{X} 4-0.014 \times 5+$ $0.206 \times 6+0.502 \times 7+0.323 \times 8+0.390 \times 9+0.048 \times 10+0.119 \times 11-$ $0.175 \mathrm{X} 12$

$\mathrm{F} 4=0.027 \mathrm{X} 1+0.079 \mathrm{X} 2-0.109 \times 3+0.305 \mathrm{X} 4-0.046 \mathrm{X} 5$ $+0.233 \times 6+0.044 \times 7-0.261 \times 8-0.007 \times 9-0.033 \times 10+0.598 \times 11$ $+0.114 \times 12$

$=0.027 \times \mathrm{b} 1+0.079 \times \mathrm{c} 10.109 \times \mathrm{d} 1+0.305 \times \mathrm{e} 10.046 \times \mathrm{f} 1+0$. $233 \times \mathrm{g} 1+0.044 \times \mathrm{h} 1-0.261 \times \mathrm{i} 1-0.007 \times \mathrm{j} 1-0.033 \times \mathrm{k} 1+0.598 \times 11+$ $0.114 \times \mathrm{m} 1$

By the standardization of treatment the original financial indicators, We obtained the function value $\mathrm{X}$. So we got 30 listed companies scores on the four common factors in the F1, F2, F3 and F4, those scores of the four public can represent 73.901 percent informationon the original data, Then the eigenvalues of each factor's contribution to the public as weight, using the following formula: $F=(28.721 \times \mathrm{F} 1$ $+22.164 \times \mathrm{F} 2+13.307 \times \mathrm{F} 3+9.710 \times \mathrm{F} 4) / 73.9$, with four factor score and calculating 30 companies obtained composite score, as shown in Table 6.(omit) $F$ is the composite performance score, F1, F2, F3, F4 are each factorscore.Based on the above formula Ranked for the Comprehensive Performance of agricultural listed companies.

\section{Conclusion}

By the previous empirical analysis, we can draw the following conclusions: The results from the factor score, we can get that 30 listed companies operating Performance and results of ranked.Among the top five composite scores They are Kai ChuangGuoJiCo, YanChangHuaJian Co, DunHuang ZhongYeCo, Guan NongGuFenCo and LuDaDi Co. KaiChuangGuo CO is Top-ranked, main reasons is its ability to have a good operation, but its profitability and capacity development are still insufficient and should be strengthened timely improved.

The number two YanChangHuaJian Co overall performance is good, its operational capability and development capacity is in the forefront of listed companies, profitability, solvency capability are also the top of ten,in addition, Dunhuang Co is more prominent in the development of capacity; LuDaDi Co's development capacity and profitability performed well.

The last five co are Yong AnLinYe Co., Xinzhong Ji Co. ZhongShuiYuYe Co. , DaHuGuFen and JiaHeGuFen Co. in the last five company, although the dahugufenCo. have outstanding performance in solvency, but because of its profitability, operational capacity and competency 
development is grossly inadequate, resulting in composite score of only -0.8575 , raked on 30 , jiahe Co's profitability, operating capacity are at the bottom of all agricultural listed companies, leading to its composite score ranking the last one ; zhongshuiyuye Co's profitability and capacity development is relatively weak; in addition, yongan linye revenue-generating capacity should be strengthened, and Xinzhong Ji'soperational capabilities and development capacity is still lacking, all thoes are need to be attent.by managers.

\section{Countermeasure and suggestion}

In conclusion,profitability, solvency, operation ability and development ability have impacted on listing Corporation operating performance

1) From the level of development capacity, agricultural listing Corporation's level have slowed down, indicator on development capacity has declined. Therefore, agricultural listed Corporation should improve the development ability in order to achieve sustainable development in the market competition, we must make full use of existing resources, and make the assets maintaining sustained. Agricultural listing Corporation should enhance the core competitiveness of enterprises according to the characteristics of their own advantages and potential,, so as to enhance the development capacity of agricultural listing Corporation

2) From the debt paying ability level, short-term debt paying ability level of agricultural listing Corporation is low, there is excessive debt problems, indicating agricultural listing Corporation is lack of short-term debt-paying ability. Recommended by improving the debt capital and equity capital ratio, optimize its capital structure, in order to improve the solvency, and strengthen the agricultural listed companies operating performance; at the same time, to maintain a reasonable proportion of short-term borrowings and long-term borrowings, coordinate relationship between financing cost and financing risk, making the solvency of enterprises remain at a reasonable level.

3) From the operating ability index, agricultural listing Corporation turnover rate of receivable accounts is generally low, some company index have relatively fluctuated. Accounts receivable turnover and the inventory turnover rate is low, accounts receivable and inventory turnover is slow, the agricultural listing Corporation assets utilization efficiency is low, which affecting the agricultural listing Corporation operations. Agricultural listing Corporation total assets turnover levels are low, according to this index, suggesting for improving the utilization rate of assets of enterprises, and improving the product's market share.

4) In terms of profitability : Agricultural listing Corporation profitability has declined, some profitability index such as net assets yield changed significantly, some listing Corporation and even appeared negative; because the current agriculture has not get rid of the weak, the average profitability level was significantly lower than the level profitability of the listing Corporation. Compared with other industries, agricultural listing Corporation should pay more attention to the profitability level, improve profitability, so that their financial competitiveness can have been strengthened.

\section{References}

[1] Liu, Yang Indian students. Listed companies in China's agricultural performance evaluation and analysis. Agricultural economy, 2006(4)pp47-52.

[2] He Yiqiang. Comprehensive evaluation of the performance of agricultural listed companies empirical analysis. Jiangxi University of Finance, 2005 (5) pp:51-53.

[3] Bergstrom. Capital subsidies and the performance of firms. Small Business Economics,2000 (14) pp:183-193.

[4] Lin Lefen. Empirical analysis of the performance of listed companies of China's agriculture. China rural survey, 2005(6) pp: 66-70.

[5] Yue Xiang. Study on performance of listed agricultural companies and incentive. Technical and economical, 26 (3) 2007.pp: 58-62. 